\title{
Analytical Review of Current Doctor Cultivation in China
}

\author{
Fei $\mathrm{Li}^{1, \mathrm{a}}$, Jingdong Zhang ${ }^{1, \mathrm{~b}}$, Danni Chen ${ }^{2, \mathrm{c}}$ \\ ${ }^{1}$ School of Information and Safety Engineering, Zhongnan University of Economics and Law, Wuhan \\ 430073, China;
}

${ }^{2}$ Wenlan School of Business, Zhongnan University of Economics and Law, Wuhan 430073, China. alifei@znufe.edu.cn, bjdzhang@znufe.edu.cn, cdaniella.chen@outlook.com

\begin{abstract}
Doctor candidates' cultivation is proved to be the crucial creative power for the national research system all over the world. In the recent ten years, the number of doctor students and graduates grow rapidly, and the number of doctors awarded in china as the result has become the highest in the world. Unfortunately, the quality of current doctor education under the mentor supervision system does not as high as the doctor graduation rate from the Chinese public viewpoints. Therefore, the mechanism of the Chinese current doctor cultivation is discussed and furthermore, we try to provide relevant analytical solutions and political recommendations to address the corresponding issues.
\end{abstract}

Keywords: Mentor supervision system; doctor cultivation; countermeasure and suggestion.

\section{Introduction}

The innovative talents cultivated under the higher education system are critical for the sustainable economic and social development all over the world. And as the essential part of the system, doctor candidates' cultivation is proved to be the crucial creative power for the national research system [1]. Compared with developed countries, Chinese doctor education system had been formally established merely since 1981 . There are nearly 0.49 million doctors awarded in China since the establishment of Chinese doctor education system. And based on the statistical result by the China Online Education, approximately $50 \%$ of the total doctor candidates are enrolled in recent five years, while the number of the enrolment and awarded doctors has increased rapidly in the most recent decade as well (Fig. 1).

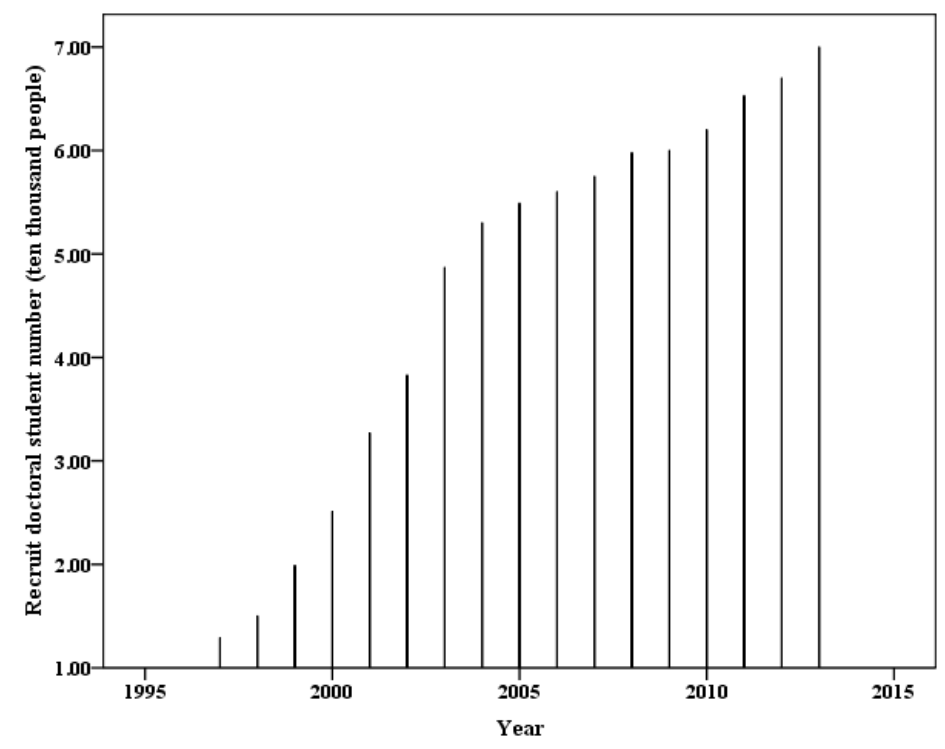

Fig. 1 Recruit doctoral student numbers in year 1997-2013

In 2008, China has overtaken the U.S. in terms of the number of awarded doctor degrees [2, 3]. It seems a marvel that China only takes 20 years to surpass the U.S. in terms of the number. However, the public opinion, for example "China is now rich in doctors, but still lack of outstanding researchers", does not agree that the marvel deserves praise. Meanwhile, the real phenomena, such as "fraud academic", "fake scientific research project", "privileges for on-job doctor candidates to get 
degree in an easier way", shock the public frequently [4]. Moreover, some doctor mentors are even using their power for self desires. All of that indicate that some doctoral supervisor or doctoral candidates become speculators of current higher education system. As a Chinese proverb from the Yanzi Chunqiu • Inner Pieces says: "It is the different soils that make the same orange seed grow up to orange in the south of Huai River while be poncirus trifoliate in the north of Huai River", the key "soil" (the current doctor cultivation system) that make fateful contribution to the China-West doctor education differences need to be discussed for proposing the feasible recommendations for improvement.

\section{Issues of Current Doctor Cultivation in China}

The four issues of current doctor training system are analyzed through field investigation and data collection:

2.1 Easy Entry and Graduation Requirements and Mass Enrolment of on-job Doctor Students. Based on The Ten Proposals for Reorganize the Higher Education Method Deeply wrote by Liu Daoyu (the former president of Wuhan University), the doctor graduation fail rate in China (about 0\%) compared with that in western countries (nearly 30\%) is extremely unreasonable, and part of that is because of the special privilege provided by degree-awarding institutions to on-job officers and businessmen so that they will graduate easily. In addition, about how to improve the quality of doctor education, he indicates that the doctor degree-awarding universities should be strictly supervised or reorganized, and at least half of those universities should be dynamically disqualified.

Certainly, some doctor cultivation institutes are following the "easy admission and strict graduation" rule. The problem mainly lies in that some education institutes that short of resources want to make extra benefits from the doctor degree-awarding power and break the basic rule as a result. The desire of some officers or businessmen such as to "upgrade their education background" easily, can be satisfied through some break-rule education institutes and finally cause the "academic corruption". Nevertheless, the non-uniform graduation requirements between on-job students and general doctoral candidates who try to obtain the $\mathrm{PhD}$ degree will inevitably make the greatly negative effects to the general doctoral candidates.

\subsection{The Unreasonable Performance indicators limit the Creativity of Students.}

Currently, there is a vicious circle in China's doctor education system. The "boss" (the mentor) continues "hiring" doctor candidates as the way to keep themselves as the qualified cultivation teachers but not really consider how to make the students better in academic studies. Once those "hired" students graduated, some of them may imitate their mentors and be the new "boss" for merely money or power.

To large extent, that vicious circle is not the original imagination of doctor supervisors but because of the unreasonable performance benchmarks and fierce competition under the current Universities' research-teach performance evaluation systems. Under that assessment system, the majority of doctoral supervisors are busy with reaching the standard like increasing number of published papers. As a result, they do not have time to concern about how to cultivate their students. Therefore, the main "outstanding" doctor candidates become who are paper machines under the thoughts of mentors without any creation of their own thinking. Consequently, without being taught how to think individually, some graduates from Dr. do not get offers and feel that they only learnt how to make papers as more as possible regardless of the quality during their four or five years' doctor degree study period.

\subsection{Lack of Courage and Faith to "Challenge the Scientific Research Frontier".}

The more the better, the current assessment benchmarks drive heavy attention to the number of papers, which lead to the "innovative papers of Chinese style". Once published a paper and mastered the key of achieving that, some doctor candidates start a journey to produce similar or even worse papers under the acquiescence of mentors and the pressure of graduation and living,. To some extent, once the repetition of making similar or even worse papers starts, the research life of those people are actually almost over. 
Obviously, mentors and their students are tending to choose a more secure and certain way rather than "challenge the scientific research frontier". The reason behind is the challenge's input-output uncertain risk. Moreover, as the increasing age of those students, the pressures from social opinion, family financial burden, finding the mate will harm their creativity and motivation to challenge and innovate as well.

\subsection{Unreasonable Material Rewards Allocation.}

As the Chinese research students' scholarships established in 2012, the fund for doctor candidates is thirty thousands RMB per person. The measures caused a big response from the relatively poor colleges and universities. After three years of implementation, it lead to several issues nowadays: the tremendous increase number versus the nearly no significant quality improvement of papers; the weak team consciousness and the intensifying competition among research teams; the high enroll rate (overcrowded) of some popular subjects versus low enroll rate (nearly zero) for other subjects that not as easy as the former ones in terms of publishing papers.

\section{Proposals about Improving Current Doctor Cultivation in China}

\subsection{Introduce the Supervision and Elimination System.}

The "strict enroll and graduation" rule need to be improved [5]. Firstly, the supervision and manage of doctor stations should be dynamically carried out and timely cancel the doctor stations that fall behind the standard performance metrics. Furthermore, to greatly reduce the value of the On-the-job Ph.D should be done in order to maintain fairness of doctoral education environment. In addation, it should continue to increase scrutiny of $\mathrm{PhD}$ thesis and enhance the penalties of "plagiarism" and other academic fraud.

\subsection{Modify the Cultivation Goal and Conduct Creative Education Method.}

Usually, Chinese doctors were derided as nerds in social opinion which is not common when to describe bachelors or masters. The key factor of that difference is that Chinese doctors' research direction is limited under current paper-first performance indicator. Compared with bachelors and masters who still have various learning choices, Chinese doctor candidates are paying almost all their attention to the knowledge under a certain direction and, they are busy making papers for graduation. Consequently, the unique study style leads them lacking of social experience and creative thoughts.

Therefore, the performance benchmarks need to be modified. Instead of counting number of papers, the quality and creativity need to be highlighted as well. In addition, some high level selective courses such as arts should be introduced to doctoral students for stimulating their creative thoughts and helping them relax [6].

\subsection{Diversifying the Members of Research Team for Challenging the Scientific Frontier.}

As the core of scientific study team, the mentor should not only have profound theoretical basis for a scientific research, but also should have the certain abilities of future design and team management. Facing problems such as simple team structure and poor management, cultivating or introducing students with various research backgrounds will add diversity and vigor to the team [6]. And through that way, maximizing the knowledge application based on the developed team probably give birth to the confidence of every team members for challenging the scientific frontier.

\subsection{Strengthen the Industrial Adaptability of Doctoral Research.}

Under the current cultivation system, doctoral students are more like the "research workers" and their research topics are usually not that valuable or practical in industry. The main reason is the disconnection between the graduation requirements and industrial needs. Hence, it is necessary to combine the graduation requirements and industrial needs together. With the suitable combination, it will help the doctoral students to position themselves in the society, clarify their personal goal, and get offers indirectly. It surely would give them courage and motivation to exploring the practical scientific without unnecessary worries.

\subsection{Stimulate Initiative Study Through Reasonable Rewards and Penalties System.}

Personally, "fairness" should come first compared with "efficiency" in the field of education. It is because that reasonable rewards and penalties system will ensure the improvement of the initiative 
and efficiency of doctoral study. But if this rewards and penalties system is unscientific and inadaptable for different disciplines, it would lead to a totally different consequence. As the addition and modification to current assessment indexes, a multi-level rewards and punishment system, including awarding high quality papers, allocating funds based on the level of contribution, should be introduced. Moreover, through setting multi-subject programs and encouraging cross-team or even cross-faculties studies [6], the creative thoughts, teammate cooperation, and sharing the extra funds to the basic subject will be achieved simultaneously.

\section{Summary}

Education is the key to the Chinese nation. Furthermore, the quality of doctor cultivation is directly related to our country's future higher education development. "Human beings are shaped by the land around them". For providing suitable "land" for elite researchers, this study listed several considerations about the current doctor education mechanism based on field investigation. And the five proposals about improving the issues of the current doctor cultivation were put forward for the really scientific research elite education.

\section{References}

[1] Luo YZ, Qian DZ. Doctoral education quality and system innovation. Jiangsu Higher Education. Vol. 1 (2007) p. 83-85. (in Chinese)

[2] Yang J. Dr. Training strategy in Britain, United States, Japan and France and the enlightenment to our country. China Youth Study. Vol. 8 (2014) p. 26-29. (in Chinese)

[3] Zhang ZK. From the number of one of the largest in the world. China Adult Education. Vol. 19 (2008) p. 9. (in Chinese)

[4] $\mathrm{Ba}$ JH. On Chinese doctoral education system reform. Journal of Shanxi Finance and Economics University (higher education edition). Vol. 12 (2009) No.4, p. 73-77. (in Chinese)

[5] Li XQ. Doctoral education quality influence factors analysis. Academic Degrees \& Graduate Education. Vol. S1 (2007) p. 27-29. (in Chinese)

[6] Wang DF. The philosophy and institution of doctoral advising in U.S.A. Journal of Higher Education. Vol. 34 (2013) No.9, p. 54-60. (in Chinese) 